\title{
Innovation Pedagogy for Universities of Applied Sciences
}

\author{
Juha Kettunen \\ Turku University of Applied Sciences, Turku, Finland \\ Email: Juha.Kettunen@turkuamk.fi \\ Received January $4^{\text {th }}$, 2011; revised February $17^{\text {th }}$, 2011; accepted February $21^{\text {st }}, 2011$.
}

\begin{abstract}
This study presents the concept of innovation pedagogy, which is a pedagogical approach developed for the universities of applied sciences. Innovation pedagogy emphasises efficient learning and the institution's external impact on regional development. It is based on customer-oriented and multi-field needs of working life; integrates applied research and development and entrepreneurship with education in a flexible way; and promotes regional and international networking. This approach is clearly wider than the traditional individual-based learning, because it emphasises group-based and networked learning to promote innovations in working life.
\end{abstract}

Keywords: Strategy Process, Innovation, Pedagogy, Learning, Higher Education

\section{Introduction}

The Finnish higher education sectors include traditional science oriented universities and universities of applied sciences. The dual model of these sectors means that the objectives of respective institutions differ. The main division of activities is that traditional science-oriented universities create new knowledge based on basic research, while the universities of applied sciences follow scientific or artistic development, apply knowledge, and produce skills so that the institution will be useful and add value for customers. Taking the wider perspective, creating new knowledge is insufficient for universities of applied sciences.

Universities of applied sciences were established to support regional development. Today, they are part of a wider community that includes social norms and cultural practices. Sociocultural theory, therefore, and the constructivist view of learning developed by Vygotsky (1978) and Piaget (2001) are natural starting points for pedagogical development. These institutions aim not only to deliver knowledge, but also develop multi-field, collaborative deep learning (Ramsden, Beswick \& Bowden, 1989; Puntambekar, 2006) in entrepreneurship and applied research and development to promote innovations (Tidd, Bessant \& Pavitt, 2001).

Recent literature and policy have both documented that an upsurge in creativity and education has taken place in European, American, Australian, and East Asian counties (Shaheen, 2010). Education policy aims to enable learners to think creatively and critically to solve problems. It should give learners the opportunity to become innovative and enterprising such that education has the real effect on society. The most dominant argument for education policy is economic achievement. Indeed, education is crucial in assisting nations attain higher employment, economic growth, and social welfare.

Strategic flexibility is the key competence to capture external information and plan proactive strategies for promoting innovations and taking action to respond to a changing environment (Sanchez, 2002). In June 2008 the Finnish Ministry of Employment and the Economy published its innovation strategy, which focuses on innovation policy and the changes and reforms nec- essary for its implementation. Another important national starting point was the internationalisation strategy prepared by the Ministry of Education and Culture. The strategic plan of the City of Turku and the Regional Programme for the Regional Council for Southwest Finland were taken into account, because the strategic plan must be aligned also with essential regional network strategies and outlines. The strategy process of the Turku University of Applied Sciences (TUAS) started in January 2009 with environmental scanning and defined the profile of the institution as innovation pedagogy.

The Finnish Ministry of Education and Culture has defined and stipulated general outlines and objectives for higher education institutions for 2010-2012. One of the objectives is that higher education institutions should be the basis of the Finnish innovation system. The higher education sectors should thus increase their collaboration with working life and other parties within the innovation system. In this context, innovations can be classified as incremental or radical (Bessant, Lamming, Noke \& Phillips, 2005).

The purpose of this study is to present the concept of innovation pedagogy, which was developed at the TUAS. Pedagogical development should be an essential element in the strategic plan and quality assurance of the higher education institution. While pedagogy should take into account the main elements of education, it should also provide a flexible framework that can be used in numerous universities of applied sciences. In this way, they can operate as regional knowledge and innovation centres and create value for their customers.

Multi-field and networked collaboration responds to the development needs of the region. Active institutions respond to development needs with project teams of applied research and development, which combine complementary knowledge of team members (Hautala, Kantola \& Kettunen, 2008). The universities of applied sciences, which want to meet multi-field customer needs, develop their processes and structures to support multi-field teams of research and development.

This study is organised as follows. Section 2 describes the development of innovation pedagogy. It explains the context, pedagogical roots and elements of innovation pedagogy. Section 3 introduces the main concepts of innovations and presents 
examples based on multi-field, group-based and networked learning which take place in applied research and development. Finally, the results of the study are discussed and summarised in the concluding section.

\section{Development of Innovation Pedagogy}

\section{Context}

The first traditional science university in Finland was established in 1640, but the universities of applied sciences were established in the beginning of the early 1990s. The pedagogical approaches developed for traditional universities, however, were not suitable for universities of applied sciences. In particular, introducing applied research and development spurred the development of pedagogical approaches that could support innovations and increase the external impact of the institution on its region. Clearly, the need emerged to develop pedagogy for universities of applied sciences.

The activities of public sector organisations have been stipulated in detail in the Act of the Universities of Applied Sciences. The internal processes and structures of public organisations should be planned based on this legislation. The Act was changed in 2003 when applied research and development was added to the statutory tasks of the universities of applied sciences. The tasks of Finnish universities of applied sciences according to the Act are as follows:

The universities of applied sciences educate experts for working life and its development needs based on scientific and artistic background, support the professional growth of students and carry out applied research and development, which serve education, support regional development, and take into account regional economic life.

The universities of applied sciences provide adult education to keep the knowledge of working life up-to-date.

The universities of applied sciences provide teacher training as stipulated.

The Act clearly refers to regional development and economic life. Universities of applied sciences, therefore, should be able to contribute to various stakeholders and networks of working life. On the other hand, applied research and development should serve education. This stipulation has led to integrating of research and development with education, which means that new learning environments are created to provide students with possibilities to participate in applied research and development.

Strategic planning produces strategic objectives and themes for a better future (Kettunen, 2004, 2006, 2008). During the strategy process at the TUAS, it became evident that the institution should develop and describe its pedagogical approaches to learning. The strategic plan and the pedagogical approach should be based on national education policy, regional strategic outlines, and the strengths of the institution. The concept of innovation pedagogy emerged and became written down as a result of the dialogue during the strategy process.

\section{Pedagogical Roots}

The pedagogical roots of innovation pedagogy can be found in the pragmatism of John Dewey (1925); learning from experience (Dreyfus \& Dreyfus, 1986); the activity theory (Engeström, 1995; Kuula, 1999); inquiry learning (Hakkarainen, Lonka \& Lipponen, 1999); learning by developing (Raij, 2007;
Kallioinen, 2008); and connectivism (Siemens, 2005). Pragmatic and experience-based learning, which are tied to inquiry and development in regional working life and networks, are essential elements of innovation pedagogy. Stauffacher, Walter, Lang, Wiek and Scholz (2006) pointed out that the student projects are more demanding than intramural learning because the projects should combine the objectives of teachers, students, and working life.

Research implies that individual learning is superior to group-based learning for relatively simple recall tasks, which favours lecturing and examinations. Individual learning takes place in lecture halls, where the teacher typically lectures and students listen, take notes and examinations, and write theses. Students typically sit passively as instructors explain and demonstrate concepts. The responsibility of learners in learning and the student ownership of the learning process are meagre. While lectures are necessary to give background knowledge, individual learning can be developed into a more meaningful experience.

Individual learning is not superior when compared to group-based learning for relatively complex problem-solving tasks. A possible explanation for this can be found in cognitive load theory (Paas, Renkl, \& Sweller, 2003, 2004). The cognitive load theory assumes that individuals cannot process an unlimited number of information elements in their working memory. A group, however, has more available processing capacity than an individual for tasks in which the relevant information must be shared among working memories so that learning can begin.

A higher education institution is not an isolated system; instead it is part of a wider community with associated social norms and cultural practices. Higher education includes actions that occur, because they are part of a particular socio-cultural setting. Socio-cultural theory and the constructivist view of learning have become increasingly popular to explain learning and development (Vygotsky, 1978; Piaget, 2001). Lave and Wenger (1991) used the term "community of practice” to encompass the social and cultural customs of a particular community and its ways of operating.

Collaborative learning is both an individual-centred and group-based approach build on constructivism and social learning theories that assume learning emerges as learners interact (Vygotsky, 1978). Group-based learning requires learners to work together to maximise achievements and accomplish a learning goal (Puntambekar, 2006). Expert assistance or scaffolding can lead learners to create innovations that require complex problem-solving skills and adapting to environmental factors.

Recent research has identified several cases where groupbased learning may be the preferred option. Kirschner, Paas, and Kirschner (2009) indentified that learning task complexity is an important factor that helps teachers select activities appropriate for group-based learning. Group-based learning is a good option when a multidisciplinary approach or diversity of expertise is needed to solve a problem or carry out a task (Kirschner, Beers, Boshuizen \& Gijselaers, 2008). Other cases appropriate for group-based learning include argumentative learning (Munneke, Andriessen, Kanselaar \& Kirschner, 2007) or when reflection (King, 2007), negotiation (Beers, Boshuizen \& Kirschner, 2007) or debating are being taught (Leitão, 2000; Veerman, Andriessen 
\& Kanselaar, 2000). Different groups of students can use different creative ways to solve the problems (Barrow, 2010).

Collaborative learning takes place when people interacting locally with one another and their environment use swarm intelligence. The concept of swarm intelligence was originally inspired by observing of various natural phenomena such as birds flocking or the insects swarmings (Bonabeau \& Meyer, 2001; Kennedy, Eberhart \& Shi, 2001). Swarm intelligence has been demonstrated as effective when solving complex problems such as scheduling, structural optimisation, multi-objective problems, and e-learning through distributed and emergent behaviour (Huang \& Liu, 2009).

The literature on networked learning goes back, at minimum, to Mason and Kaye (1990). Networked learning can be supported by different technologies such as computer communications software, which brings learners together in a web of interaction and links to resources (Fowell \& Levy, 1995; Hammond, 1997). Networked learning offers the opportunity for students to articulate their own experiences and share them with other learners. The sharing of knowledge and ideas is central to this approach.

Networked learning is not, however, confined to the using information and communication technology. Advanced learning takes place when learners are well-connected to their environment and the roles and expectations among members of an advanced networked learning community are aligned. A networked learning community is particularly relevant in professional education, where the idea of reflecting on personal knowledge and professional know-how is particularly important.

Individual, group-based, and networked learning reflect the levels of surface and deep learning proposed by Ramsden, Beswick, and Bowden (1989). The core is individual learning, which is typically represented in traditional science universities, where the students listen to lectures and memorise them for examinations. This kind of individual-centred learning can easily be considered surface learning. Surface learning focuses on the signs and unrelated parts of tasks. Information for assessment is simply memorised. Facts and concepts are associated unreflectively and principles are not distinguished from examples. The task of learning is treated as an external imposition and emphasis is external to the demands of the assessment.

Learning in professional higher education is typically group-based learning, which falls closer to the concept of deep learning. The emphasis of deep learning is internal and emanates from within the student. The focus of learning is in practical things and relates theoretical ideas to everyday experience. The learning relates and distinguishes evidence and argument. Group-based learning relates the new knowledge to previous courses and knowledge and organises and structures the content into a coherent whole.

The original metaphor of surface and learning introduces a rather simplistic dichotomy and conveys as such little about the learning process. Bourner (2003) explores the nature of reflective learning and advances the idea that the distinction between surface and deep learning can be generalised to the domain of reflective learning. Results by Cassidy (2006) revealed a positive correlation between a deep approach to learning and self-assessment skill demonstrating the importance of learning style. Bennet and Bennet (2008) use the terms of surface, shallow and deep learning. At the surface level, the focus is on facts, data, concepts and the information that can be memorised and applied. At the shallow level, the focus is on social interactions through, for example, conversations, dialogues, debates, and the flow of ideas that emerges in communities and teams. At the deep level, the focus is on the learning from effortful practice and lived experience.

The pedagogical foundations support the argument that the learning style of the universities of applied sciences should be developed towards shallow and deep learning to include group-based and networked learning. The purpose of the universities of applied sciences is to support regional development by taking into account economic and working life. Freyens and Martin (2007) emphasised that often necessary knowledge is created in a social environment as a result of efficient and multidisciplinary activities. Networked learning also extends traditional collaborative learning to include electronic networks and databases.

Figure 1 depicts individual, group-based, and networked learning across the basic tasks of the universities of applied sciences. The tasks of these institutions are described with various dimensions, which include educating young people; supporting professional growth; and conducting applied research and development, artistic work, adult education and teacher training. These tasks cross individual, group-based, and networked learning.

Individual learning in lecture halls and examinations is broadened to group-based learning, including entrepreneurship training, applied research and development, and community service. Networked learning includes activities in real working environments such as internships. Networked learning also includes electronic networks and platforms. In addition, students often participate in learning situations in which they collaborate with students from other higher education institutions.

\section{Elements of Innovation Pedagogy}

The concept of innovation pedagogy is new, but it includes all the important elements of higher education. Such elements have been both implicit and underlying features of organisational culture for at least a decade at the TUAS. The new concept was needed, however, because the old approaches to learning were not suitable for the institution. Indeed, the TUAS wanted to increase its external impact on the region and promote innovations. Taking into account the mission of universities of applied sciences to support regional development, educational curriculum should be developed to reach out to and engage with development activities in the region.

The statement of innovation pedagogy is expressed in the strategic plan of the TUAS as follows:

"Entrepreneurship, applied research and development, internalisation are integrated with education: Innovation pedagogy based on the customer-oriented and multi-field operation of the TUAS supports the innovations utilised in the workplaces. The flexible structures of curricula and alternative forms of study enable the integration of entrepreneurship, applied research and development and community service with education."

The underlying elements of innovation pedagogy have been derived from the Act of the Universities of Applied Sciences, which describes applied research and development, the development of education, entrepreneurship training, and interna- 


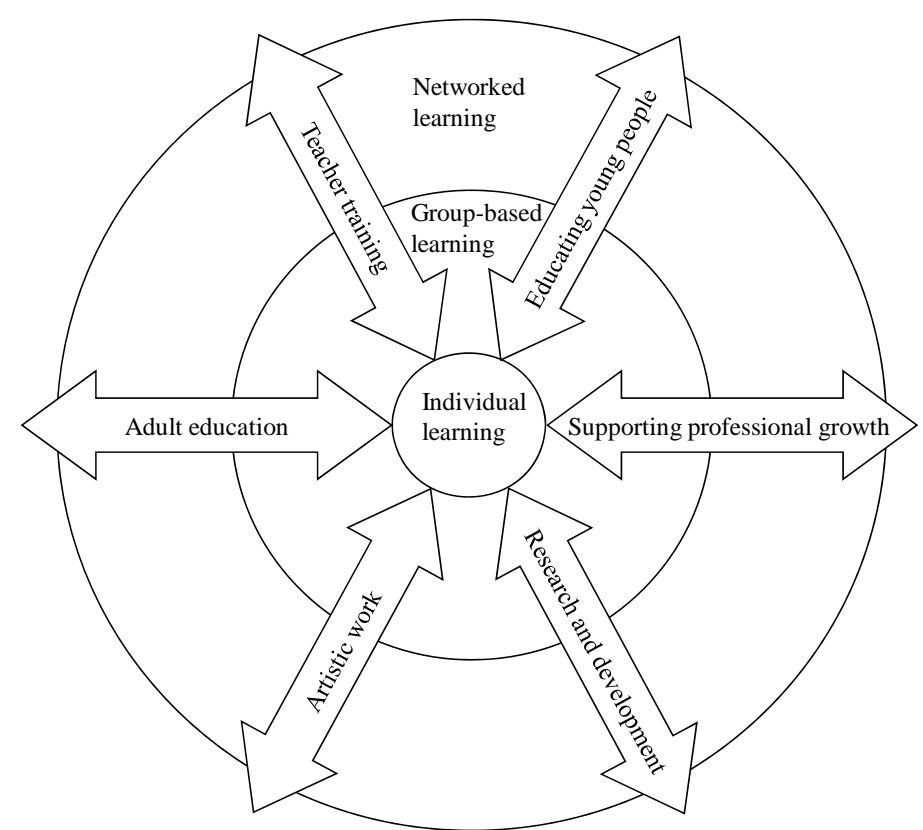

Figure 1.

Individual, group-based, and networked learning.

tionalisation. The multi-field operation is intrinsic to the internal processes and structures of the TUAS. The underlying elements of innovation pedagogy are as follows:

1) Multi-field operation. The needs of customers do not typically follow a single subject, a degree programme, or a particular field of study. Innovations can be created as the result of different parties and organisational units in networked projects. The multi-field faculties of the universities of applied sciences can promote applied research and development.

2) Applied research and development. Research and development projects are integrated with education utilising regional knowledge and innovation networks. The results of research and development are evaluated not only through publications, but also based on how they add value for customers.

3) Flexible curricula. Educational development is based on the strategic outlines of innovation pedagogy and quality assurance, which ensure strategic objectives are achieved. The flexible curricula should also enable entrepreneurial and international activities.

4) Entrepreneurship. Entrepreneurship and community service are promoted by integrating them into education, which responds to the needs of working life. Entrepreneurship is supported by flexible curricula enabling the path of entrepreneurship studies during the degree programme. The objective of entrepreneurship training is that students acquire capabilities to start their own business.

5) Internationalisation. Each degree programme within the institution offers international courses. The objective of studies is to provide students with capabilities for activities in international networks and business.

The profile of the TUAS was defined in the strategy process for 2009-2010 as innovation pedagogy based on multi-field activities, where entrepreneurship, applied research and development, and internationalisation combine with education to promote innovations in the working places of Southwest
Finland. The profile is specified with focal areas of knowledge.

\section{Promoting Innovations}

The universities of applied sciences have a mandate to engage in applied research and development, even though they have limited funding for such activities. An innovative solution is that research and development is integrated with higher education so that students can participate in projects and learn in new learning environments. The Ministry of Education and Culture encourages this policy; indeed, its indicators for performance-based funding include integrating research and development with education.

The research and development programmes of the TUAS are based on the following focal areas of the faculties:

- $\quad$ applied information and communication technology

- $\quad$ biocompetence and business know-how

- $\quad$ expertise in health care and medication

- $\quad$ lifelong well-being services

- $\quad$ marine environment and construction expertise

- $\quad$ working life based approaches to creative arts.

The institution and faculties allocate financial resources to these focal areas. In addition, external funding is sought to supplement internal funding.

Innovations can be classified to incremental and radical (Tidd, Bessant \& Pavitt, 2001; Bessant, Lamming, Noke \& Phillips, 2005). Incremental innovations are those in which a new feature is added to existing products, services, or processes using existing knowledge. The quality culture, which is based on continuous improvement supports, incremental innovations. Radical innovations are those in which a new product, service, or process is developed. Often radical innovations are based on explorative research. Networked operations and the combination of different competencies exist in creating innovations. 
Universities of applied sciences are designed to develop their regions and promote innovations of working life. This interpretation is given as well by the Organisation for Economic Co-operation and Development (OECD) (2007), which stated that innovation is an extramural practice that institutions can promote with its activities. Organisational innovations can also occur within higher education institutions, but the main emphasis is on external impact. Innovations of working life are important, because they are considered as having a prominent effect on economic achievement.

Applied research and development of the universities of applied sciences should be integrated with education so that the institutions could respond to the development needs of their regions. The projects combine the knowledge of the entire value chain including basic research, applied research and development and business. In the next section, some typical examples are shown how the university of applied sciences can successfully promote regional development with innovations in group-based and networked learning.

\section{Example 1. Broadcasting for the $21^{\text {st }}$ century (B21C)}

The Digital Video Broadcasting - Terrestrial (DVB-T) television transmission system has delivered wireless, digital TV services since its inception in 1997 in almost every continent. The emergence of new consumer applications such as mobile $\mathrm{TV}$ and the convergence of various wireless technologies are leading the DVB community to evaluate both the suitability of the existing DVB-T system to accommodate emerging situations and consider the benefits that new technologies could bring to DVB-T.

One of the challenges of converting from analogue to digital broadcasting is to maintain broad geographical coverage for both stationary and nomadic terminals, including handheld terminals, and provide reliable service for mobile receivers in automotive and train applications. The present Digital Video Broadcasting - Handled (DVB-H) system represents the industry's first attempt to accommodate consumer demands for broadcasts to a handheld terminal. It has been proposed that by adopting both DVB-H and satellite broadcasting technologies it should be possible to deliver a high online operating system for all applications and terminals, in both urban and rural areas, to meet consumer requirements. This project primarily produces an incremental product innovation, because it adds a new technological feature to existing consumer applications, but it also extends the existing services to nomadic terminals.

The B21C project aims to support the standardisation process of the extended DVB transmission systems within the rapidly evolving broadcasting landscape. Developing and standardising extended DVB systems will require extensive work in the areas of channel modelling, simulation, laboratory testing, and field trials. The B21C project has clear the objective to sustain evolution of DVB as demanded by emerging applications.

The B21C is a European project with 35 partners from Finland, Sweden, Germany, France, Spain, England, Hungary, and Italy. The Finnish participants include Nokia, Digita, Elektrobit, the University of Turku, the Tampere University of Technology, and the Turku University of Applied Sciences. The project is a Celtic initiative belonging to the EUREKA Cluster and is dedicated to end-to-end telecommunication solutions. Celtic initiates and runs both privately and publicly funded information and tele- communications research and development projects. The project combines the knowledge of the entire value chain including higher education and research, software development, component manufacturers, and operators. The project provides students with the possibilities to take advantage of the working life, better supervision and international learning environment. The students can also apply their knowledge in practise which is not possible in conventional lecture-based education.

Example 2. Promoting Environmental Management Awareness: A Transatlantic Perspective

Awareness of environmental issues among students is a great challenge, because pollution has long been recognised as a threat to human health and ecosystems. Enhanced environmental management is needed to take advantage of the increasing number of business opportunities in the environmental industry. To achieve these objectives, international cooperation and curriculum development was started between European and Canadian higher education institutions. The output of the project can be classified as an incremental service innovation, because it develops existing curricula.

The project helps students gain in-depth practical learning and experience regarding European and Canadian approaches and practices to environmental management. The project helps the participating students shape the understanding of environmental issues in both the public and private sectors. The overall gain is to learn and experience the environmental policies, attitudes, and practices of organizations in management operations.

Awareness of environmental problems helps students understand environmental business practices from an international perspective. The subject matter of this project covers the expertise of business management, environmental technology, and natural sciences. The combined approach offers students the skills and competencies needed to manage environmental strategies and operations in small- and medium-sized enterprises and the public sector. The curriculum development provides students with the opportunities to integrate the project with education, and benefit from group-based and networked learning in an international multi-field environment.

The project also promotes international exchanges among students and faculty members in the partner institutions. The European partners are the Turku University of Applied Sciences, Institut Polytechniqua LaSalle Beauvais, and Universiteit Van Amsterdam. The Canadian partners are Université de Moncton, Mount Royal College, and Lauretian University. On-going communication between partner institutions is occurring throughout the project. The partners are committed to developing a web-based learning environment that exchange students and other students at the home institutions can use. Both mobile and non-mobile people can benefit from the outputs of the project.

\section{Example 3. Virtual Elderly Care Services on the Baltic islands (VIRTU)}

The VIRTU project uses the cross-border cooperation in developing joint solutions to common problems in the field of social and health care services in archipelago areas. The ageing population, long distances, and the lack of a qualified labour force combined with limited budgets are challenges of that sparsely populated archipelago areas of Finland and Estonia 
face. VIRTU is a multidisciplinary project that combines the knowledge of social and health care with information and communication technology to solve these demographic problems. These issues are also common also in many other countries.

Developing processes of social and health care using modern information and communication technology is necessary; otherwise, such municipalities cannot provide the quality and attainability of services with the available financial and human resources. Hospital care, for example, is much more expensive than care at home. From the elderly point of view, it is important to maintain and improve the standard of living and support healthy, safe, and socially rich living at home rather than reverting to hospitalisation.

The project creates a new, cost-efficient procedure based on virtual technologies that benefits the elderly, their relatives, municipalities, and health and social care professionals in the archipelago. Students and professionals are encouraged to take advantage of the technological innovations as a part of their daily work. In addition, the project develops the service into a profitable and transferable business concept. The output of the project can be classified as a radical process innovation, because it creates a new process to meet the challenges of ageing population. The project provides students with the opportunities for group-based and networked learning in a multi-field and cross-border environment. The learning style creates capabilities for students to develop innovative well-being services for elderly people.

The new process is created as a collaboration with the Novia University of Applied Sciences, the Laurea University of Applied Sciences, the Åland University of Applied Sciences, the municipalities of Sipoo, Eckerö, Naantali, and Saltvik from Finland and Foundation Tuuru, Kuressaare Regional Social Welfare Center representing the City of Kuressaare, Estonia and Saaremaa Business Development Foundation representing the rest of the Saaremaa municipalities, Estonia. The project is funded by the Central Baltic Interreg Programme.

\section{Conclusion}

Teaching and learning within higher education has developed markedly during the last few decades. Establishing the universities of applied sciences in Finland in the early 1990s was a process in which a higher education institution was created based on the knowledge of many diversified vocational schools. Creating of a new sector of higher education started a movement of pedagogical development toward multidisciplinary education. Including applied research and development to support regional development in the Act of these institutions was a remarkable change that led to integrating of applied research and development, entrepreneurship, community service, and international activities with education.

These changes in higher education and its operational environment have increased pressure to develop the pedagogical approaches within the universities of applied sciences. This study describes the emergence of innovation pedagogy, which supports customer-oriented regional development and innovations in working life. Innovation pedagogy was developed in the strategy process of the TUAS. The approach integrates applied research and development and entrepreneurship with flexible curricula to meet the multi-field customer needs in both regional and international networks.

The students can apply their knowledge in group-based and networked learning to promote regional development which is not possible in conventional lecture-based education.

Innovations typically emerge in multidisciplinary and networked collaboration among higher education institutions, companies, and other organisations. Innovations may reflect that organisations are adopting environmental changes, which enforce experts to develop new products, services, and processes. On the other hand, innovations may require that partners from the entire innovation chain participate in research and development. The incremental or radical innovation of products, services, and processes may be entwined with one another. For example, new products may require the development of new services. The universities of applied sciences have an important role to promote innovations in group-based and networked learning.

\section{References}

Barrow, L. H., (2010). Encouraging creativity with scientific inquiry. Creative Education, 1, 1-6. doi:10.4236/ce.2010.11001

Beers, P. J., Boshuizen, H. P. A., \& Kirschner, P. A. (2007). The analysis of negotiation of common ground in CSCL. Learning and Instruction, 17, 427-435. doi:10.1016/j.learninstruc.2007.04.002

Bennet, D., \& Bennet, A. (2008). The depth of knowledge: Surface, shallow or deep? VINE: The Journal of Information and Knowledge Management Systems, 38, 405-420.

Bessant, J., Lamming, R., Noke, H., \& Phillips, W. (2005). Managing innovation beyond the steady state. Technovation, 25, 1366-1376. doi:10.1016/j.technovation.2005.04.007

Bonabeau, E., \& Meyer, C. (2001). Swarm intelligence: A whole new way to think about business. Harvard Business Review, 79, 106-114.

Bourner, T. (2003). Assessing reflective learning. Education + Training, 45, 267-272.

Cassidy, S. (2006). Learning style and student self-assessment skill. Education + Training, 48, 170-177.

Dewey, J. (1925). Experience and nature. LaSalle. IL: Open Court.

Dreyfus, H. L., \& Dreyfus, S. E. (1986). Mind over machine: The power of human intuition and expertise in the age of the computer. Oxford: Basil Blackwell

Engeström, Y. (2005). Developmental work research. Expanding activity theory in practice. Berlin: Lehmanns Media.

Fowell, S. P., \& Levy, P. (1995). Computer-mediated communication in the information curriculum: An initiative in computer supported collaborative learning. Education for Information, 13, 193-210.

Freyens, B., \& Martin, M. (2007). Multidisciplinary knowledge transfer in training multimedia projects. Journal of European Industrial Training, 31, 680-705. doi:10.1108/03090590710846666

Hakkarainen, K., Lonka, K., \& Lipponen, L. (1999). Tutkiva oppiminen. Älykkään toiminnan rajat ja niiden ylittäminen. Porvoo: WSOY.

Hammond, M. (1997). Developing networked learning within higher education: A case study of an electronic forum for university staff. Teaching in Higher Education, 2, 243-257. doi:10.1080/1356215970020306

Hautala, J., Kantola, M., \& Kettunen, J. (2008). Challenges of multidisciplinary and innovative learning. In G.F. Ollington (Ed.), Teachers and teaching: Strategies, innovations and problem solving (pp. 377-389). Hauppauge, NY: Nova Science Publishers.

Huang, Y-M., \& Liu, C-H. (2009). Applying adaptive swarm intelligence technology with structuration in web-based collaborative learning. Computers \& Education, 52, 789-799. doi:10.1016/j.compedu.2008.12.002

Kallioinen, O. (2008). Oppiminen learning by developing toimintama- 
llissa. Laurea publications, A 61. Helsinki: Edit Prima.

Kennedy, J., Eberhart, R. C. \& Shi, Y. (2001). Swarm intelligence. San Francisco: Morgan Kaufmann Publishers.

Kettunen, J. (2004). Bridge building to the future of Finnish polytechnics. Journal of Higher Education Outreach and Engagement, 9, 43-57.

Kettunen, J. (2006). Strategic planning of regional development in higher education. Baltic Journal of Management, 1, 259-269. doi:10.1108/17465260610690917

Kettunen, J. (2008). A conceptual framework to help evaluate the quality of institutional performance. Quality Assurance in Education, 16, 322-332. doi:10.1108/09684880810906472

King, A. (2007). Scripting collaborative learning processes: A cognitive perspective. In F. Fischer, K. Ingo, H. Mandl and J.M. Haake (Eds.), Scripting computer-supported collaborative learning: Cognitive, computational and educational perspectives (pp. 14-37). New York: Springer. doi:10.1007/978-0-387-36949-5_2

Kirschner, P. A., Beers, P. J., Boshuizen, H. P. A., \& Gijselaers, W. H. (2008). Coercing shared knowledge in collaborative learning environments. Computers in Human Behavior, 24, 403-420.

Kirschner, F., Paas, F., \& Kirschner, P. A. (2009). Individual and group-based learning from complex cognitive tasks: Effects on retention and transfer efficiency. Computers in Human Behavior, 25, 306-314. doi:10.1016/j.chb.2007.01.028

Kuula, A. (1999). Toimintatutkimus: Kenttätyötä ja muutospyrkimyksiä. Tampere: Vastapaino.

Leitão, S. (2000). The potential of argument in knowledge building. Human Development, 43, 332-360. doi:10.1159/000022695

Lave, J., \& Wenger, E. (1991). Situated learning: Legitimate peripheral participation. New York: Cambridge University Press.

Mason, R., \& Kaye, A. (1990) Towards a new paradigm for distance education. In L. Harasim (Ed.), Online education: Perspectives on a new environment. New York: Praeger.

Munneke, L., Andriessen, J., Kanselaar, G., \& Kirschner, P. A. (2007). Supporting interactive argumentation: Influence of representational tools on discussing a wicked problem. Computers in Human Behavior, 23, 1072-1088. doi:10.1016/j.chb.2006.10.003

Puntambekar, S. (2006). Analyzing collaborative interactions: Divergence, shared understanding and construction of knowledge. Computers \& Education, 47, 332-351.

doi:10.1016/j.compedu.2004.10.012
OECD (2007). Higher education and regions: Globally competitive, locally engaged. Paris: OECD Publishing.

Paas, F., Renkl, A., \& Sweller, J. (2003). Cognitive load theory and instructional design: Recent developments. Educational Psychologist, 38, 1-4. doi:10.1207/S15326985EP3801_1

Paas, F., Renkl, A., \& Sweller, J. (2004). Cognitive load theory: Instructional implications of the interaction between information structures and cognitive architecture. Instructional Science, 32, 1-8. doi:10.1023/B:TRUC.0000021806.17516.d0

Piaget, J. (2001). The psychology of intelligence. London: Routledge.

Raij, K. (2007). Learning by developing. Laurea publications, A 58. Helsinki: Edit Prima.

Ramsden, P., Beswick, D., \& Bowden, J. (1986). Effects of learning skills interventions on first year university students’ learning. Human Learning, 5, 151-164.

Sanchez, R. (2002). Understanding competence-based management, Identifying and managing five modes of competence. Journal of Business Research, 57, 518-532. doi:10.1016/S0148-2963(02)00318-1

Shaheen, R. (2010). Creativity and education. Creative Education, 1, 166-169. doi:10.4236/ce.2010.13026

Siemens, G. (2005). Connectivism: A learning theory for the digital age. International Journal of Instructional Technology \& Distance Learning, 2, 3-10.

Stauffacher, M., Walter, A. I., Lang, D. J., Wiek, A., \& Scholz, R. W. (2006). Learning to research environmental problems from a functional socio-cultural constructivism perspective: The transdisciplinary case study approach. International Journal of Sustainability in Higher Education, 7, 252-275. doi:10.1108/14676370610677838

Tidd, J., Bessant, J., \& Pavitt, K. (2001). Managing innovation: Integrating technological market and organizational change. Chicester: Wiley.

Veerman, A. L., Andriessen, J. E. B. \& Kanselaar, G. (2000). Learning through synchronous electronic discussion. Computers \& Education, 34, 269-290. doi:10.1016/S0360-1315(99)00050-0

Vygotsky, L. S. (1978). Mind in society: The development of higher psychological processes. In M. Cole, V. John-Steiner, S. Scribner and E. Souberman (Eds.). Cambridge, MA: Harvard University Press. 